\title{
Analysis of interconnected configuration for penetration of distributed generation
}

\author{
Bilal Asghar Farooqi ${ }^{1,2 *}$, Mohamad Radzi Bin Ahmad ${ }^{1}$ and Muhammad Ali ${ }^{3,4}$ \\ Department of Electrical and Electronics Engineering, Universiti Teknologi Petronas, Malaysia ${ }^{1}$ \\ Department of Information System, SBE, University of Management and Technology, Lahore, Pakistan ${ }^{2}$ \\ Electrical and Electronics Engineering Department, Nigde Omer Halisdemir University, Turkey ${ }^{3}$ \\ Department of Electrical Engineering, University of Azad Jammu and Kashmir, Pakistan ${ }^{4}$
}

Received: 15-September-2020; Revised: 18-January-2021; Accepted: 20-January-2021

(C)2021 Bilal Asghar Farooqi et al. This is an open access article distributed under the Creative Commons Attribution (CC BY) License, which permits unrestricted use, distribution, and reproduction in any medium, provided the original work is properly cited.

\begin{abstract}
This paper visualizes the feasibility of the proposed interconnected distributed power system configuration, which aims at incorporating the electricity generation from renewables and to cater to low voltage areas of radial distribution network. The shortcoming of existing traditional radial systems is inconsistent load distribution and technical viability in incorporating renewable sources without disturbing the power system. Sustainable development is achieved with improvement in the prevailing distribution system. Maximum potential benefits in terms of demand-supply balance and integrating renewables can be achieved by selecting properly placed and optimally sized distributed generation sources in a distribution network. The generation facility is selected as per the geographical profile of the location and placed on the weakest node. The weakest node is the low voltage profile region where the maximum output of the integration of power sources is beneficial. In this paper, the ZIP model-based methodology is applied to feeder loads on the data set of the distribution grid of the National University of Science \& Technology (NUST), Islamabad, Pakistan. The comparative analysis is performed on a radial network of NUST distribution grid and compared with a simulated interconnected distribution system of the same distribution network on MATLAB software as a case study to observe the performance of interconnected power systems. This analysis results in better voltage profiles for interconnected networks, compared to radial networks. That said, incorporating a Distributed Generation (DG) source in the interconnected network builds a substantial impact on the distribution system voltage profile. The efficacy of the proposed interconnected system confirms the performance improvement of the distribution power system. The VSI values for interconnected systems give better results which is further justified by the machine learning algorithm, Logistic regression. The simulation results indicate that the Interconnected system encourages penetrations of solar, wind, gas turbine, and other renewable sources near the low voltage end in the distribution system.
\end{abstract}

\section{Keywords}

Distributed power system, Distributed power generation, Interconnected system, Logistic regression.

\section{Introduction}

In the modern era, the usage of maximum electricity is a symbol of economic development linked with technological growth. The rapid proliferation of electronic devices across the world will increase electricity demand in the future. The goal of any power utility (generation, transmission, distribution) is providing seamless power supply by meeting supply-demand balance. Traditionally, power demand is accomplished via generation facilities run by fossil fuels and non-renewable resources.

*Author for correspondence

1
Additionally, demand response schemes are used in peak time to accommodate the expected rise of demand thereby decreasing the chance of system failure, and utilizing the power more efficiently.

During the past few decades, transformations towards renewables are encouraged by experts, policymakers, and government agencies to increase generation capacity with a clean green environment. The achievement of this transformation will be a difficult task. Renewable energy is a green clean source of energy. It is available in the form of wind, solar, ocean waves, and bio-waste. These resources are intermittent as solar energy is linked with solar 
radiation and wind is flowing with variance in speed. Moreover, renewables can be standalone with batteries or grid-connected with high implementation costs. Standalone systems are less reliable. Renewable penetration imposes the additional financial burden of operations and maintenance $(\mathrm{O} \&$ $\mathrm{M})$ on the utilities. Thus, the cost of promoting a clean environment and reducing carbon footprint is high at this point. However, with an increase in renewable penetration, this cost can be reduced. Additionally, renewable penetration requires special care in designing to avoid reverse power flow into the grid. Therefore, the concept of the microgrid is encouraged in the US and Europe to maintain and establish stable power flow and power quality.

Technological advancement in electrical generation, transmission, and distribution is linked with growth in the economy. In underdeveloped countries, the traditional grid lacks the infrastructure to integrate renewables. High voltage at generation is lowered to a standardized voltage value while the secondary voltage is variable. The voltage and frequency standards in Pakistan are $220 \mathrm{~V}$ and $50 \mathrm{~Hz}$. The microgrid consists of one master control unit, which manages the power system with low voltage/medium voltage, variable load, devices to store energy, and distributed generation sources. However, managing grid frequency and power balance at a low voltage level is still a challenge [1]. The microgrid can be arranged in an islanded mode (isolated from the grid) and grid-connected mode (connected to the grid). The output range in MWs of small-scale units of DGs is usually located near end-users or customers. To avoid reverse power flow, the DGs are operated within the safe operating voltage limits. Electricity networks can absorb $10-50 \%$ penetration of DG safely [2]. That said, voltage profile and stability can be improved by DG integration into the grid at optimal locations [3-6].

There are two types of distribution system configuration; radial and interconnected. Generation on one side and load on the opposite side comprises a radial system in a single line, whereas, interconnected distribution networks meet the power needs of the customers by adding reliability into the system by interconnecting multiple radial systems. The radial system is easy to implement, inexpensive, and easily managed. However, an interconnected system is difficult to implement due to cost, complexity, continuous monitoring, and management [7, 8]. In the case of excessive power flow, the difference in voltage phasors between supply substations may result in overloading of feeder segments. During planned maintenance, service interruption, and overloading, feeder interconnection supports load transfer [9, 10]. Thereby, penetrating DG on the weakest node will increase power quality, power stability, and economics of the system. Pakistan is a developing country with a weak and aging electrical infrastructure.

Following are the objectives of this research,

- A price decrease for customers after renewable penetration in the long run.

- DG penetration at load end during network congestion via implementing small-scale power projects.

- Incorporation of DG without disturbing the grid stability, power quality, and voltage profile into a distribution system.

\section{Literature review}

The electric power network consists of generation, transmission, and distribution. The focus of this manuscript is based on feeder connection topologies within a distribution system. Famous connection schemes are Radial, Parallel, Ring, and Interconnected. Radial Feeder Distribution System has a centralized generating station, simple configuration, and is cost-effective but not supporting power supply feeder in case of contingency. The distribution System with parallel feeders has high installation costs, improved reliability, and loadsharing capabilities. Ring Feeders Distribution System provides reliability that involves feeders with altered paths. Loop is formed in the feeders that run through the load area feeding distribution transformers and low voltage fluctuations at the consumer's end. In the Interconnected Distribution System, a feeder has many generating stations that energize the feeder ensuring reliability [11]. Interconnected configuration in a distributed system provides advantages like simple switching, fewer components for protection, and low fault current. However, reliability is better than radial distribution systems. To meet power requirements during increased demand, any feeder can be fed from the other generating station, substation, or distributed generation. Therefore, the transformation of radial configuration to interconnected for better voltage profile requires identification of the weakest nodes within the distribution network to penetrate DG. DGs penetration will lead to supply-demand balance at any time. For finding load distribution, the finite element method is used for experimental and numerical analysis [12]. 
Weak bus identification facilitates in finding out the node with voltage collapse as a major drawback. For nodes needful of new sources with reactive power installed, this facilitation helps in optimal reactive power planning. Voltage stability index (VSI) is used to determine the strength of the power system infrastructure [13, 14]. Planning efforts on the integration of renewables and distributed generation are motivated by pressures to reduce $\mathrm{CO} 2$ emissions [15].

Initially, the distribution system design has no generation source at the consumer end. However, after the introduction of distributed generation sources, the voltage conditions, switchgear fault ratings, and the power flow through the network shows significant improvement within the power system. Moreover, generation at the consumer end will result in a reduction of transmission line losses and build positive economic impact [16]. DGs placement is a hot topic among power system researchers due to its impact on node voltages, power flow, and reliability. Load capacity in [17] acts as a placement strategy. Its optimal location for placement minimizes the loss of a single feeder during peak load conditions in the proposed strategy. The location is selected irrespective of its load capacity. Optimal placement is based on the admittance matrix. However, it cannot find out the exact size and capacity of DG directly. We will discuss DG placement in our future work.

Technical losses and non-technical losses can be observed in a distribution system. Resistive losses of power conducting material are called technical losses. Frauds in energy meters, secret connections, and inefficient energy measurement are few non-technical losses. Feeder reconfiguration, DG placement, reactive power compensation, and smart meter incorporation reduces power losses.

\section{Methods}

The manuscript aims to decrease power system losses by finding locations of the weakest nodes, increase reliability by incorporating interconnected systems in a distribution network using the ZIP model. In the ZIP model, node voltages are measured for constant impedance $(\mathrm{Z})$, current $(\mathrm{I})$, and power $(\mathrm{P})$. It is a static polynomial load model with three types of load characteristics and is given in equation (1) and equation (2) [18]. The nominal values of the load active, reactive power, and voltage $\operatorname{are} \mathrm{P}_{\mathrm{i}}, \mathrm{Q}_{\mathrm{i}}$, and $\mathrm{V}_{\mathrm{o}}$.

$$
P=P_{i}\left[P_{1}\left(V / V_{o}\right)^{2}+P_{2}\left(V / V_{o}\right)+P_{3}\right]
$$

$$
Q=Q_{i}\left[Q_{1}\left(V / V_{o}\right)^{2}+Q_{2}\left(V / V_{o}\right)+Q_{3}\right]
$$

Based on the type of load, parameters can be obtained.

\subsection{Constant impedance load model}

$\mathrm{P}_{1}, \mathrm{Q}_{1}$ equals 1. $\mathrm{P}_{2}, \mathrm{Q}_{2}, \mathrm{P}_{3}, \mathrm{Q}_{3}$ equals 0. $\mathrm{P}_{1}+\mathrm{P}_{2}+\mathrm{P}_{3}$ equals to 1 and $Q_{1}+Q_{2}+Q_{3}$ equals 1 . Both powers (active and reactive) are proportionate to the square of the voltage. Substitution of above values in equation (1) and (2) results in,

$$
\begin{aligned}
& P=P_{i} V^{2} \\
& Q=Q_{i} V^{2}
\end{aligned}
$$

\subsection{Constant current load}

$\mathrm{P}_{2}, \mathrm{Q}_{2}$ equals 1. $\mathrm{P}_{1}, \mathrm{Q}_{1}, \mathrm{P}_{3}, \mathrm{Q}_{3}$ equals 0. $\mathrm{P}_{1}+\mathrm{P}_{2}+\mathrm{P}_{3}$ equals 1 and $Q_{1}+Q_{2}+Q_{3}$ equals to 1 since active and reactive powers are proportional to voltage. Substitution of above values in equation (1) and (2) results in,

$$
\begin{aligned}
& P=P_{i} V \\
& Q=Q_{i} V
\end{aligned}
$$

\subsection{Constant power load}

$\mathrm{P}_{3}, \mathrm{Q}_{3}$ equals 1. $\mathrm{P}_{2}, \mathrm{Q}_{2}, \mathrm{P}_{1}, \mathrm{Q}_{1}$ equals 0. Powers (active and reactive) is voltage-independent so $\mathrm{P} 1+$ $\mathrm{P}_{2}+\mathrm{P}_{3}$ equals $1, \mathrm{Q}_{1}+\mathrm{Q}_{2}+\mathrm{Q}_{3}$ equals 1 . Substitution of above values in equation (1) and (2) results in,

$P=P_{i}$
$Q=Q_{i}$

The rest of the paper is organized as follows. The general overview of the system model is provided in Section 3. A case study is discussed in Section 4 The algorithm is proposed in Section 5. Simulation results are demonstrated in Section 6. Finally, the manuscript is concluded in Section 7.

The model simulated in this work represented loads as nodes and load voltage is taken in per unit. In Figure 1, the increase in distance of the radially connected network from the source decreases the voltage gradually.

It is important to note that voltage rises in some instances where parallel branches are located. From Figure 2, it can be seen that node voltage at the foremost feeder goes to the bottom point at node 19 . Node 19 is the weakest node and best suited for DG penetration based on VSI radial and interconnected value as shown in Table 1. 


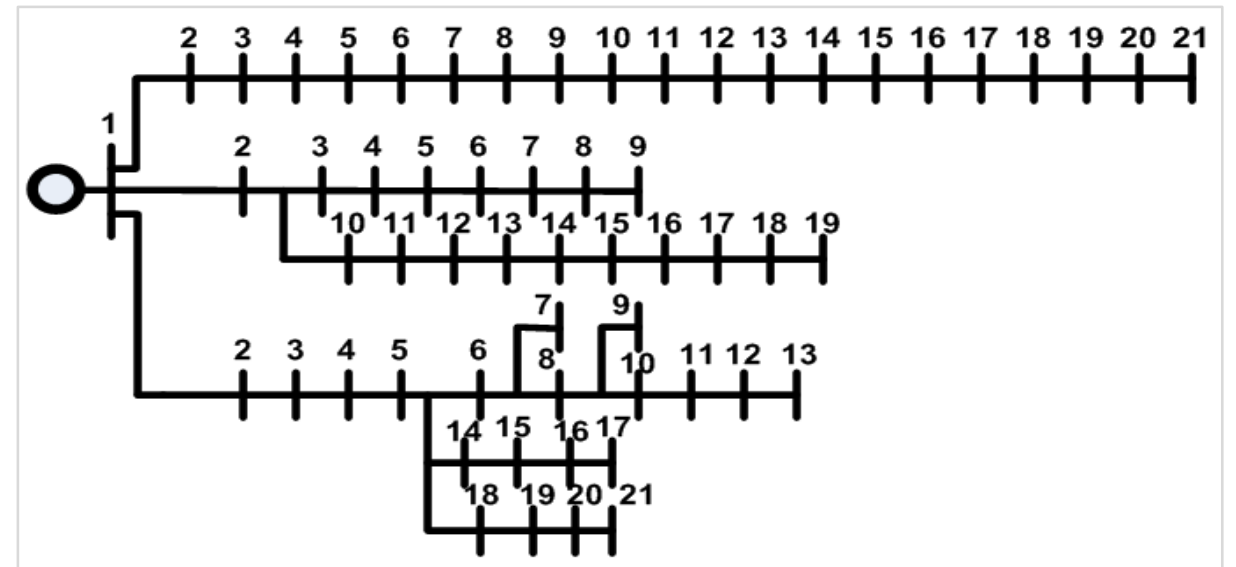

Figure 1 Radial distribution system (NUST)

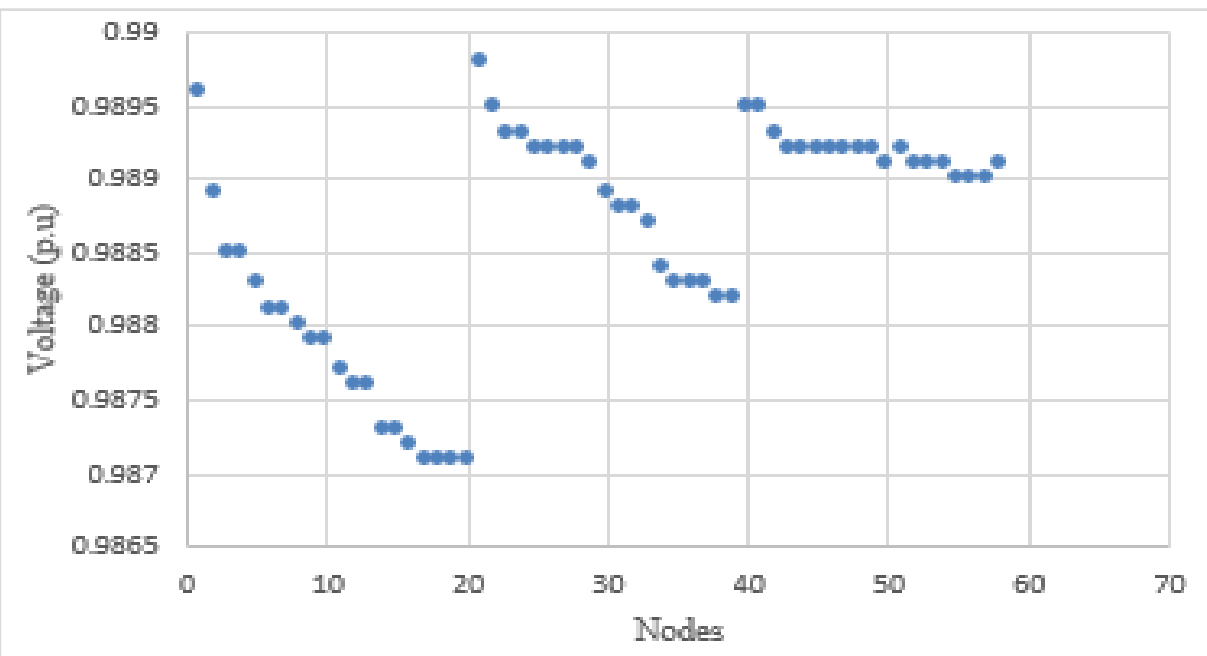

Figure 2 Voltage profile of radial distribution system (NUST)

Table 1 Value of voltage stability index

\begin{tabular}{llll}
\hline S. No & Node numbers & VSI Radial & VSI Interconnected \\
\hline 1 & 18 & 0.9875 & 0.9886 \\
2 & 19 & 0.9855 & 0.9843 \\
3 & 20 & 0.9845 & 0.9897 \\
\hline
\end{tabular}

The VSI radial and interconnected values are calculated using equation (9) and equation (10) [19].

$$
\begin{aligned}
V S I(R)= & \left\{\left|V\left(a_{1}\right)\right|^{4}-4\left\{P\left(a_{2}\right) X(i i)-Q\left(a_{2}\right)\right.\right. \\
& R(i i)\}^{2}-4\left\{P\left(a_{2}\right) R(i i)\right. \\
& \left.\left.+Q\left(a_{2}\right) X(i i)\right\}\left|V\left(a_{1}\right)\right|^{2}\right\} .
\end{aligned}
$$

$$
\begin{gathered}
\operatorname{VSI}(I)=\sum_{j=1}^{n_{l}}\left(\frac{V_{s b}}{n}\right)^{4}-\frac{4}{n} \sum_{j=1}^{n_{l}}\left(\frac{V_{s b}}{n}\right)^{2}\left[\left(\frac{E_{a}}{G_{a}}\right)+\left(\frac{F_{a}}{H_{a}}\right)\right] \\
-\frac{4}{n}\left[\left(\frac{E_{a}}{G_{a}}\right)-\left(\frac{F_{a}}{H_{a}}\right)\right]>0 .
\end{gathered}
$$

Interconnection between feeders involves nodes with variable profiles. Our reference feeders are zigzag generally and parallel in some areas with minimum distance. There is no fixed pattern of spreading feeder lines. Line spreading depends on the needs of the customers and design specifications. Areas with 
parallel feeders are interconnected to save costs. The calculation of the minimum distance between two feeders comes out to be approximately 35 meters.

In Figure 3, Feeder-1 is connected with Feeder-2 at nodes with the minimum distance. Additionally, Feeder-2 is connected with Feeder-3, and Feeder-3 is connected with Feeder-1 following the same criteria. Figure 4, Figure 5, and Figure 6 depict simulated results of both radial and interconnected configurations of 3 feeders with 7 cases of interconnections within the NUST micro-grid.

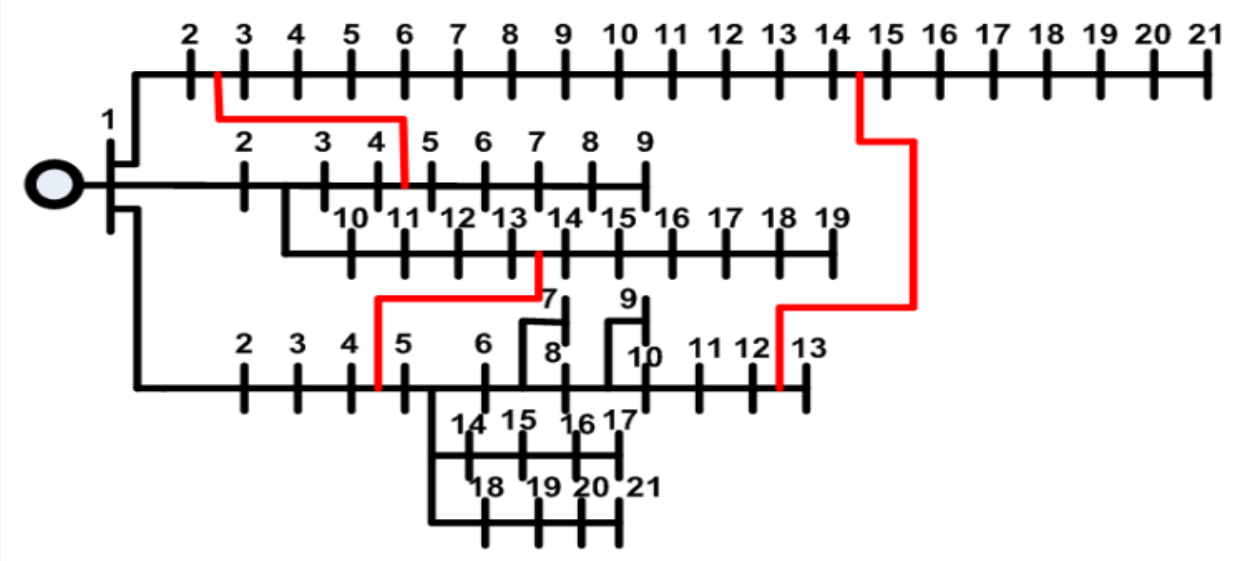

Figure 3 Interconnected distribution system (NUST)

\section{Results and discussion}

Simulations were carried out on Intel core-i5 CPU@2.1 with 8GB RAM on MATLAB 2019a on 64 Bit OS. ZIP Model is used for the analysis of the grid and simulation is carried out for constant power, constant impedance, and constant current. The simulation includes three feeders with branches at different locations to feed the load. Step down transformer is used at load end as per requirement. Figure 4 (a) depicts the result of the interconnection for Feeder-1 and Feeder-2. Improvement in voltage level is observed from node 21 to 26 in Feeder-2. The improvement is observed in nodes with near connection points on the feeders.

Figure $4(b)$ depicts the result of the interconnection for Feeder-2 and Feeder-3. The same pattern is observed in which voltage is improved between nodes 30 to 37 . However, a significant decrease is observed between nodes 24 to 56 .

Figure 4 (c) depicts the result of the interconnection for Feeder-1 and Feeder-3. The voltage levels of all the nodes increase considerably for this interconnection of Feeder-1. However, the Feeder-3 voltage level at nodes decreases. It is observed that this interconnection improves voltage level for only Feeder 2 nodes 22,28,30.
Figure $5(a)$ depicts the result of interconnections for Feeders-1, 2 and Feeders-2, 3. Voltage levels of nodes for Feeder-2 are increased as compared to previous cases and nodes for Feeder-3 decrease following the same pattern as Figure 4 (c).

Figure $5(b)$ depicts the result of interconnections for Feeders-1, 2 and Feeders-1, 3. The voltage increase in Feeder-1 follows Figure 4 (c) while the voltage decrease in Feeder-3 follows Figure 4 (c) and Figure 5(a).

Figure 5(c) depicts the results of interconnections for Feeders-2, 3, and Feeders-1, 3. Voltage improvement for feeder 1 follows Figure 5(b) and Figure 4(c). However, a voltage decrease is pronounced for the nodes in Feeder-3 as compared to Figure 4 (c), Figure $5(a)$, and Figure $5(b)$. All the nodes for Feeder-2 depict improvement in voltage profile as compared to Figure $4(a, b, c)$. Figure 5 depicts two feeder's interconnection of two separate nodes on different feeders. Nodes with less VSI for interconnected systems as compared to radial systems are considered as the weakest node. Interconnected systems will perform better in the identification and location of the weakest nodes to penetrate DG for supply-demand balance.

Figure 6 depicts the results of interconnections for Feeders-1, 2, and 3. Change is prominent in Feeder-1 
Bilal Asghar Farooqi et al.

and Feeder-2. However, a decrease in voltage level is seen for Feeder-3. Conclusively, voltage stability indices helped in identifying the weakest nodes as discussed in the cases. Moreover, VSI values showed that the interconnected system configuration supports the identification of weakest nodes for DG penetration easily and increases generation capacity.

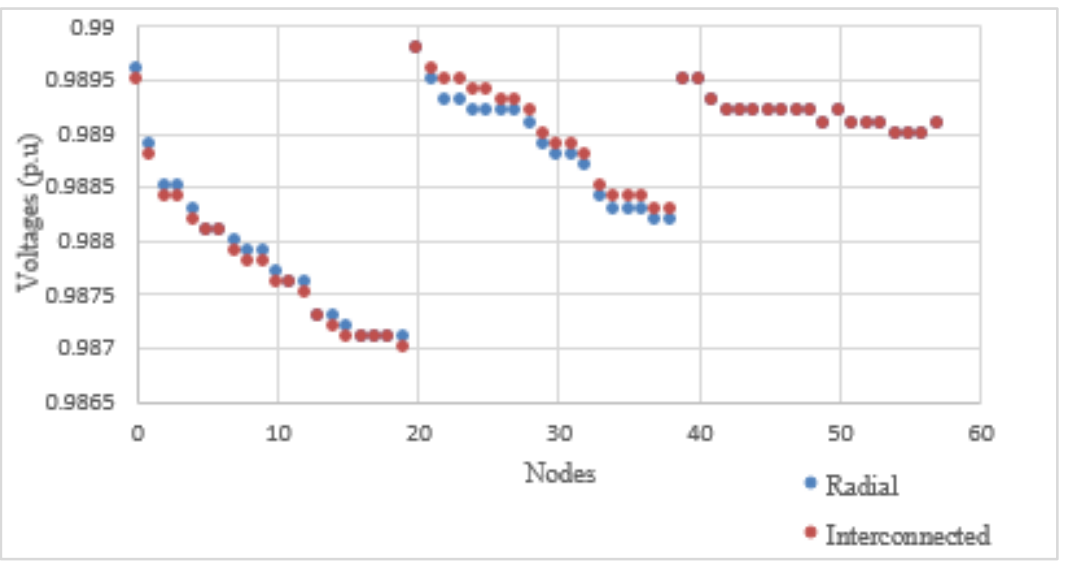

Figure 4 (a) Radial and single interconnected Voltage profiles of the distribution system of Feeder 1 and 2

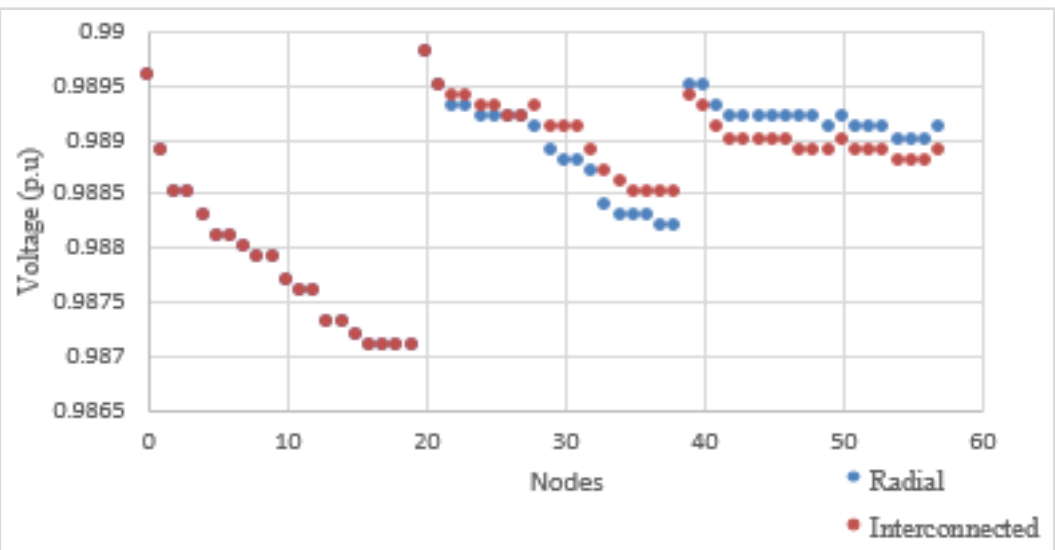

Figure 4 (b) Radial and single interconnected Voltage profiles of the distribution system of Feeder 2 and 3

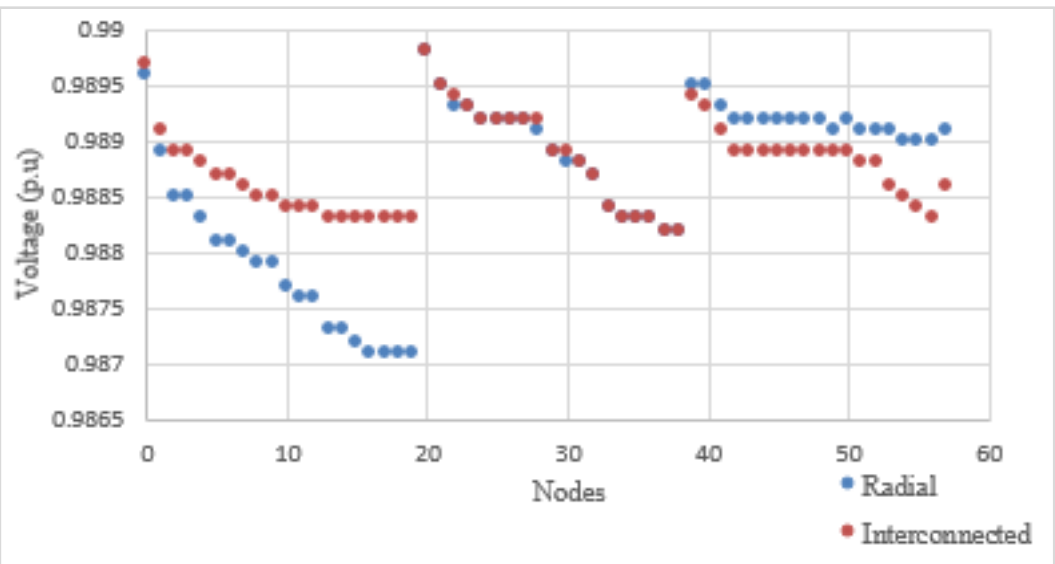

Figure 4 (c) Radial and single interconnected voltage profiles of the distribution system of Feeder 1 and 3 
International Journal of Advanced Technology and Engineering Exploration, Vol 8(74)

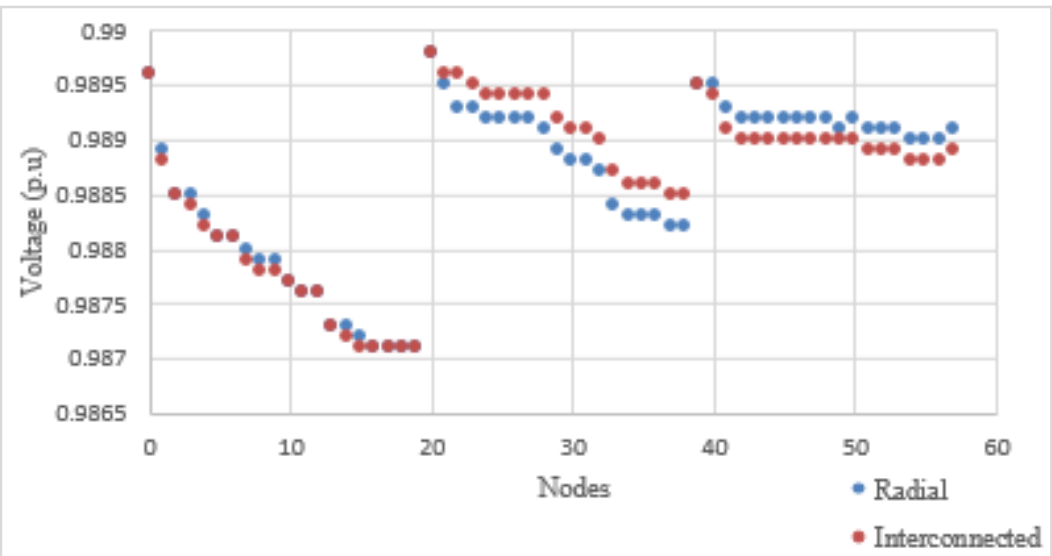

Figure 5 (a) Radial and dual interconnected voltage profiles of distributed system of feeder 1 and 3 with Feeder 2 and 3

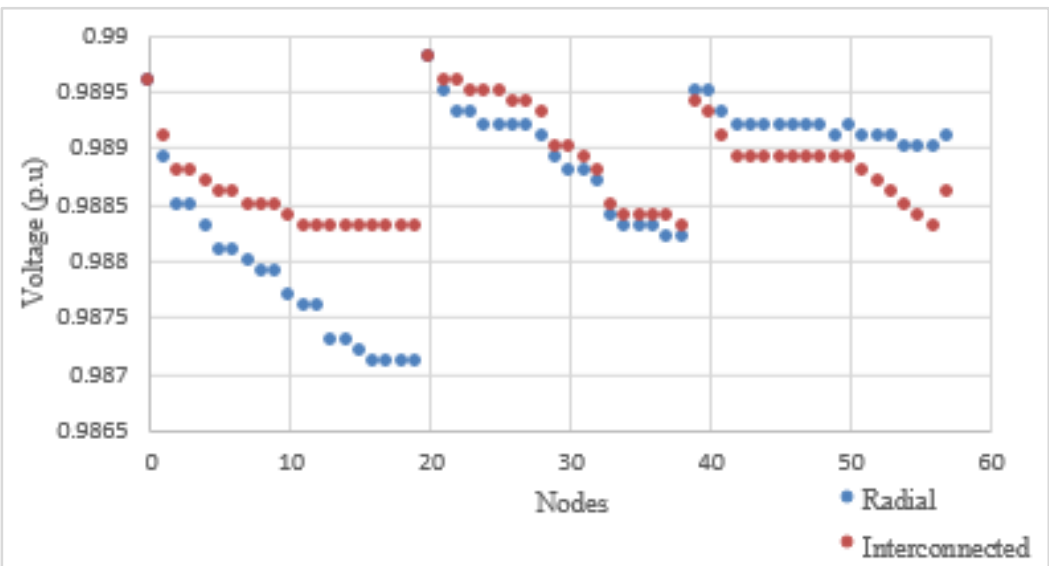

Figure 5 (b) Radial and dual interconnected voltage profiles of distributed system of feeder 1 and 2 with Feeder 1 and 3

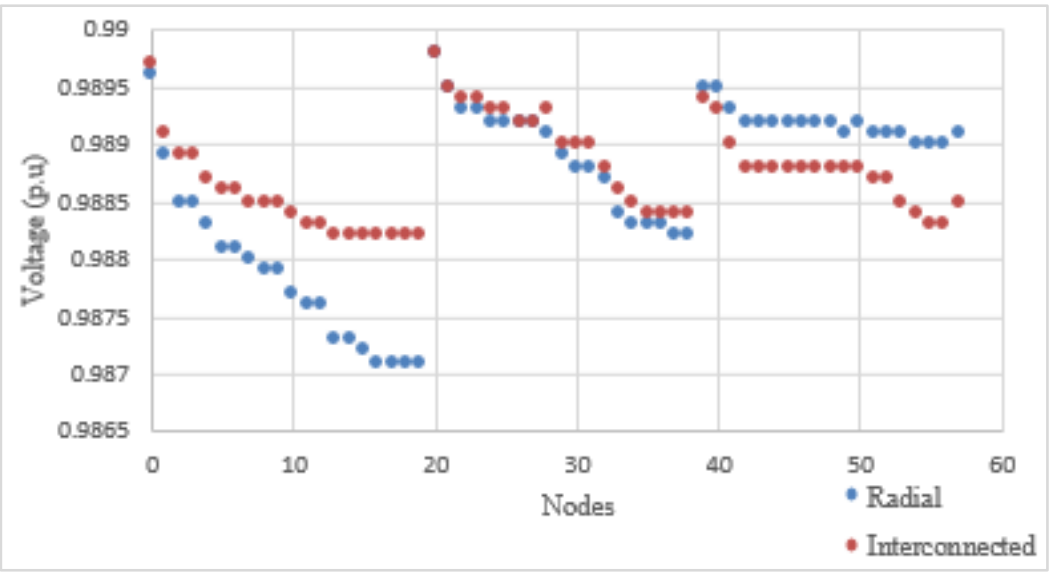

Figure 5 (c) Radial and dual interconnected voltage profiles of distributed system Feeder 2 and 3 with Feeder 1 and 3 
Bilal Asghar Farooqi et al.

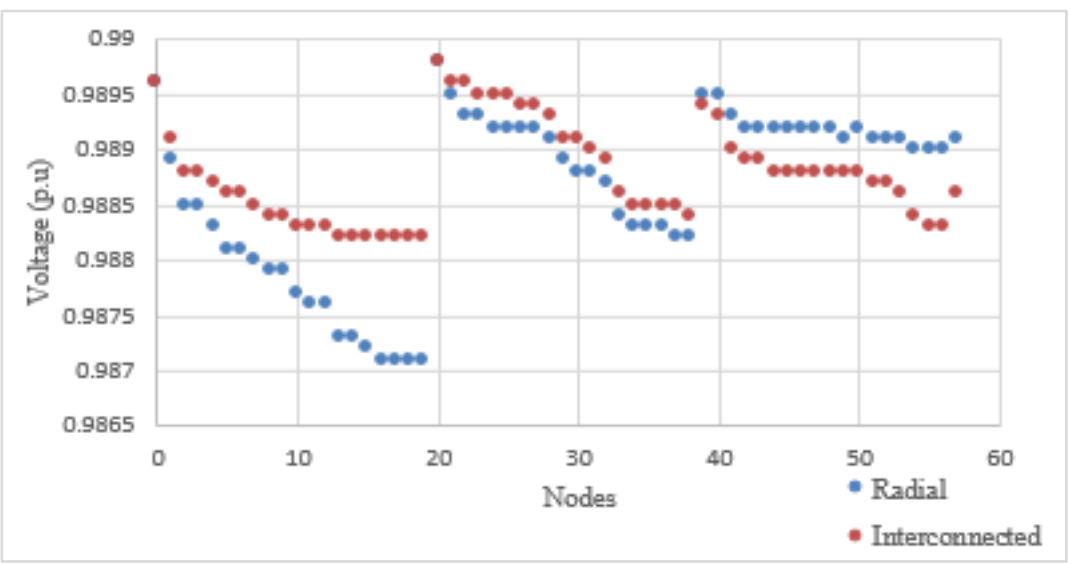

Figure 6 Radial and triple interconnected voltage profiles of distribution system

\section{Analysis}

Off-grid activities are encouraged in Pakistan. Today, research is going on independent private power distribution networks to study the transformation impact of the radial systems to interconnected systems. National university of science and technology (NUST) Islamabad has its Distribution Grid.

In this study, the NUST distribution system is examined. It constitutes multipurpose buildings with expected load growth. The loads and customers in NUST are fed radially via an underground distribution system from the grid with 3 distribution feeders. During an outage, radial infrastructure is not reliable; the whole feeder may switch off resulting in power disruption. Differing in the radial system, more stability and reliability can be observed with the interconnected system. Water and Power Development Authority (WAPDA) and Independent Power Producers (IPPs) in Pakistan are responsible for generation, NTDC for transmission, and DISCOs for distribution. NUST is located in Islamabad and the distribution company responsible for its distribution is Islamabad Electric and Power Supply
Company (IESCO). The underground distribution system at the NUST grid energizes 51 transformers. $132 \mathrm{kV}$ stepped down to $220 \mathrm{~V}$ near the load. We propose to interconnect the feeders for improved system stability and reliability. For DG penetration, VSI is used for weakest node identification, and the index proposed by Chakravarty gives better results for it [18]. Interconnection among feeders can be done with closely located feeders to reduce cost and customer distress. In our simulation, feeders are interconnected, the distance among consecutive feeders is premeditated, and the least distance nodes are interconnected under 7 scenarios.

Development in civil infrastructure directly influences power infrastructure by congestion of feeders and an increase in demand for electricity. Planned renewable energy generation projects will transform NUST into a self-sustainable microgrid. For effective utilization of renewable energy resources and optimum output, a radial distribution network can be transformed into an interconnected distribution network. Table 2 shows the feeders and load details of the NUST grid.

Table 2 Feeders information (NUST)

\begin{tabular}{llll}
\hline S. No & Feeder number & Length (ft.) & Buildings load \\
\hline 1 & 1 & 16371 & 18 \\
2 & 2 & 19183 & 16 \\
3 & 3 & 13904 & 17 \\
\hline
\end{tabular}

The computational procedure performed in this paper is given below,

Step 1: Radial data of the distribution system and simulation data of the interconnected system is taken for analysis.
Step 2: Load flow studies using the constant $\mathrm{Z}$ load model using equation (3) and (4).

Step 3: Load flow studies using the constant I load model using equation (5) and (6).

Step 4: Load flow studies using the P load model using equation (7) and (8). 
Step 5: Load flow studies using the ZIP load modeling equation (2) and (3).

Step 6: Calculation of node voltages of both radial and interconnected distribution power system for step 2 to step 6.

Step 7: Comparison via logistic regression for future prediction

The VSI values of both radial and interconnected systems are used as input to the logistic regression algorithm. The output of our simulation results in VSI demarcation of both radial and interconnected systems. From Figure 7, it is clear for Feeder-1 that VSI of 17 out of 20 nodes are better for interconnected systems. Computational Analysis via multiple machine learning algorithms will be performed in the future to find out probable values of case-specific voltage stability index [20]. K-Means clustering [21], Support Vector Machine (SVM), decision tree, random forest, and multilayer perception (MLP) algorithms [22] will be used in the future for creating clusters of similar and different
VSI values for comparative studies. Finally, the incorporation of innovation in the power industry with the addition of Information and Communication Technologies (ICT) in terms of sustainable development will have a great impact on power distribution management [23].

The limitations of approach used in this paper are,

- Urban bias

- Limited benefits to the poor

- Regional disparities in the distribution system

Therefore, the transformation from radial to interconnected systems with multiple generations will help in catering demand with minimum customer suffering, less $\mathrm{O} \& \mathrm{M}$ cost, and non-intermittent power delivery. After identification of the weakest node, DG is suggested to be penetrated at the weakest nodes.

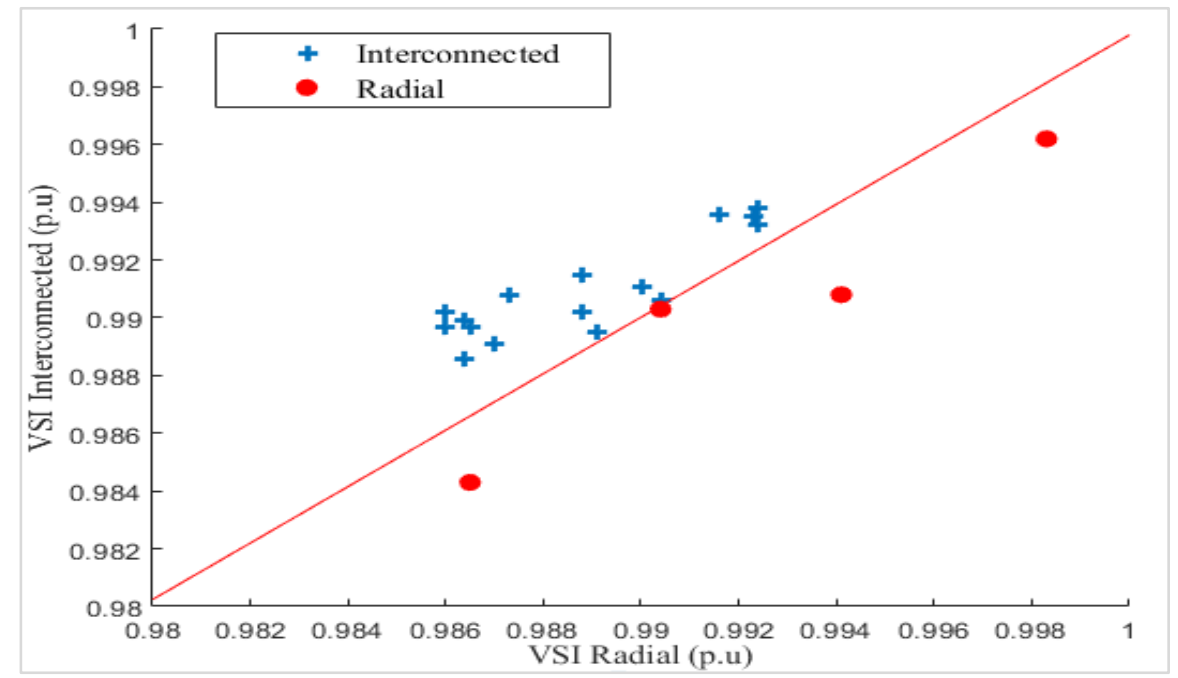

Figure 7 Logistic regression analysis

\section{Conclusion and future work}

The distribution system focuses on efficient planning and smooth operations. Modern systems incorporate renewables into the system for demand-supply balance and promoting clean energy initiatives. This manuscript indicates the probable location of the weakest nodes for DG placement in an interconnected distribution system. Simulations were carried out via the ZIP model on radial and interconnected systems on MATLAB to evaluate and compare results based on the VSI values. The interconnected system has better VSI values than the radial system.

Logistic regression further justified the VSI values for the analysis. Changes in the voltage profile after the connection of feeders were evaluated and compared in seven cases. The feeder's reliability of service can be improved, a better voltage profile will be maintained throughout the system and improvement will be observed after utilization of renewable energy sources on low voltage profile areas to meet power demand. In our future work, DG will be penetrated and machine learning will be used 
for the analysis of voltage profiles on radial and interconnected systems.

\section{Acknowledgment}

The authors would like to acknowledge Universiti Teknologi Petronas (UTP) Malaysia for sponsoring this research work.

\section{Conflicts of interest}

The authors have no conflicts of interest to declare.

\section{References}

[1] Vinothkumar K, Selvan MP, Srinath S. Impact of DG model and load model on placement of multiple DGs in distribution system. In international conference on industrial and information systems 2010 (pp. 508-13). IEEE.

[2] Quezada VM, Abbad JR, Roman TG. Assessment of energy distribution losses for increasing penetration of distributed generation. IEEE Transactions on Power Systems. 2006; 21(2):533-40.

[3] Selvan MP. Planning and operation of distributed generations in distribution systems for improved voltage profile. In IEEE/PES power systems conference and exposition 2009 (pp. 1-7). IEEE.

[4] Vittal E, O'Malley M, Keane A. A steady-state voltage stability analysis of power systems with high penetrations of wind. IEEE Transactions on Power Systems. 2009; 25(1):433-42.

[5] Ayres HM, Freitas W, De Almeida MC, Da Silva LC. Method for determining the maximum allowable penetration level of distributed generation without steady-state voltage violations. IET Generation, Transmission \& Distribution. 2010; 4(4):495-508.

[6] Enslin JH. Interconnection of distributed power to the distribution network. In IEEE PES power systems conference and exposition 2004 (pp. 726-31). IEEE.

[7] Van Thong V, Van Dommelen D, Driesen J, Belmans R. Using dynamic simulation to study the penetration level of distributed energy resources. In Russia power tech 2005 (pp. 1-6). IEEE.

[8] Celli G, Ghiani E, Mocci S, Pilo F. Multi-objective programming to maximize the penetration of distributed generation in distribution networks. In proceedings of the international conference of CIRED electricity distribution 2009.

[9] Ramesh L, Chowdhury SP, Chowdhury S, Song YH, Natarajan AA. Voltage stability analysis and real power loss reduction in distributed distribution system. In IEEE/PES transmission and distribution conference and exposition 2008 (pp. 1-6). IEEE.

[10] Vykuka R, Tesarova M. Evaluation of power distribution along interconnected middle voltage feeders. In international scientific conference on electric power engineering 2016 (pp. 1-6). IEEE.
[11] Juanuwattanakul P, Masoum MA. Increasing distributed generation penetration in multiphase distribution networks considering grid losses, maximum loading factor and bus voltage limits. IET Generation, Transmission \& Distribution. 2012; 6(12):1262-71.

[12] Patil SB, Patil SR. Experimental and numerical analysis of a load distribution along the length of contact in involute spline shaft. International Journal of Advanced Technology and Engineering Exploration. 2019; 6(51):30-44.

[13] Chen YL. Weak bus oriented reactive power planning for system security. IEE Proceedings-Generation, Transmission and Distribution. 1996; 143(6):541-5.

[14] Aziz T, Saha TK, Mithulananthan N. Distributed generators placement for loadability enhancement based on reactive power margin. In conference proceedings IPEC 2010 (pp. 740-5). IEEE.

[15] Manfren M, Caputo P, Costa G. Paradigm shift in urban energy systems through distributed generation: methods and models. Applied Energy. 2011; 88(4):1032-48.

[16] Balamurugan K, Srinivasan D, Reindl T. Impact of distributed generation on power distribution systems. Energy Procedia. 2012; 25:93-100.

[17] Jun-fang Z, Si-min D, Yin-li H, Guang H. Research on distributed generation source placement. In international conference on sustainable power generation and supply 2009 (pp. 1-4). IEEE.

[18] Paleti S, Yadav MA, Potli M. Benefit of network reconfiguration on three feeder radial distribution system. In international conference on advanced computing and communication systems 2015 (pp. 16). IEEE.

[19] Chakravorty M, Das D. Voltage stability analysis of radial distribution networks. International Journal of Electrical Power \& Energy Systems. 2001; 23(2):12935.

[20] Chahar R, Kaur D. A systematic review of the machine learning algorithms for the computational analysis in different domains. International Journal of Advanced Technology and Engineering Exploration. 2020; 7(71): 147-64.

[21] Kumari I, Sharma V. An efficient ICKM approach for similarity measurement and distance estimation based on k-means. International Journal of Advanced Technology and Engineering Exploration. 2020; 7(64):73-8.

[22] Mathur S, Badone A. A methodological study and analysis of machine learning algorithms. International Journal of Advanced Technology and Engineering Exploration. 2019; 6(51):45-9.

[23] Hba R, Idrissi MA, Ghaib MK, Manouar A. ICT sustainable management: towards a better alignment with the sustainable development strategy. International Journal of Advanced Technology and Engineering Exploration. 2020; 7(71):165-81. 


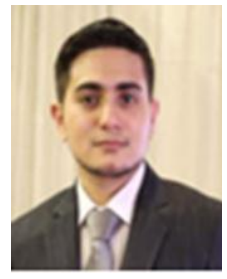

Bilal Asghar Farooqi is a $\mathrm{PhD}$ scholar at the Department of Electrical and Electronics Engineering, Universiti Teknologi PETRONAS, Malaysia. He received a Bachelor's degree in Electrical Engg. (Communication) from the University of Engineering \& Technology Peshawar, Pakistan in 2014, and a Masters in Electrical Engineering (Power) from the National University of Science and Technology, Pakistan. He is also associated with the University of Management and Technology, Lahore, Pakistan. He has diverse experience in both industry and academia. His current research interests are the Battery Management System, Electric Vehicle, Machine Learning, and Artificial Intelligence.

Email: bilalasghar@outlook.com

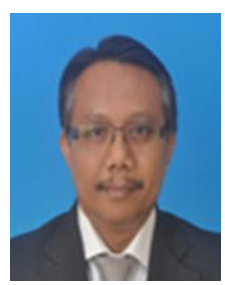

Dr. Mohamad Radzi Ahmad received his BSc. in Electrical Engineering from Purdue University Indianapolis USA in 1991, MSc. in Electronics System Design Engineering from Universiti Sains Malaysia in 2010, and PhD in Electrical and Electronics Engineering from Universiti Teknologi PETRONAS Malaysia in 2014. Dr Ahmad is currently a Senior Lecturer attached to the Department of Electrical and Electronics Engineering, Universiti Teknologi PETRONAS, Malaysia. His main research interests are in the vibration-based Energy Harvesting, power management circuit for hybrid energy harvester. He had 20 years of industrial experience with multi-national companies such as Intel, Avago, Fairchild, and Komag.

Email: mohamadradzi.ahmad@utp.edu.my

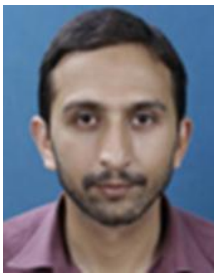

Muhammad Ali completed his BSc in Electronics Engineering from UET Peshawar, Pakistan in 2008 and MSc in Electrical Engineering from CECOS University Peshawar, Pakistan in 2013. Currently he is $\mathrm{PhD}$ scholar at Department of Electrical and Electronics Engineering, Niğde Ömer Halisdemir Üniversitesi, Niğde, Turkey. $\mathrm{He}$ is also associated with Department of Electrical Engineering, University of Azad Jammu and Kashmir Muzaffarabad, Pakistan since 2014. His current research interests include Smart Grid Communication, 5G Communication, $\mathrm{mm}$ Wave Communication System, Physical Layer Security and Hybrid Precoder Design.

Email:muhammad.ali@mail.ohu.edu.tr 